\title{
Desempenho agronômico e heterose de genótipos de cebola
}

\author{
Marcos V Faria'; Rafael Gustavo F Morales ${ }^{1}$; Juliano Tadeu V de Resende ${ }^{1}$; Daniel S Zanin ${ }^{1}$; Cícero B de \\ Menezes $^{2}$; Romulo F Kobori ${ }^{2}$ \\ 'UNICENTRO- CEDETEG, Depto. Agronomia, C. Postal 3010,85040-080 Guarapuava-PR; mfaria@unicentro.br; moralescefet@ \\ yahoo.com.br; jresende@unicentro.br; zanin.suek@hotmail.com; ${ }^{2}$ Sakata Seed Sudamerica, C. Postal 427, 12906-840 Bragança Paulista- \\ SP; cicero.menezes@sakata.com.br; romulo.kobori@sakata.com.br
}

\section{RESUMO}

A utilização de híbridos de cebola no Brasil ainda é recente e são escassas as informações referentes aos ganhos por heterose. Contudo, a primeira etapa para a exploração da heterose é a avaliação do germoplasma disponível. Devido à necessidade de genótipos adaptados às condições climáticas paranaenses, o presente trabalho teve como objetivo avaliar o desempenho agronômico de 19 híbridos e 50 linhagens de cebola, bem como o ganho heterótico de seis desses híbridos avaliados na região Centro-Sul do Paraná. O delineamento experimental foi em blocos casualizados com três repetições. Foi avaliada a produção e a massa média de bulbos, a classificação comercial, a cerosidade das folhas e o ciclo. De modo geral os híbridos foram superiores às linhagens na produtividade e massa média de bulbos e apresentaram menor ciclo. O ganho heterótico nos híbridos ficou evidenciado nos cruzamentos avaliados, indicando que híbridos podem ser viáveis para cultivo na região. Os híbridos 2572, 2573 e 2578 são promissores, pois aliam alta produtividade, ciclo mais precoce e melhor classificação dos bulbos. As linhagens 2507-1 e 2983 proporcionam elevado ganho heterótico para a produtividade do híbrido 2857, o qual foi classificado no grupo de genótipos mais precoces, demonstrando a existência de correlação inversa entre esses dois caracteres.

Palavras-chave: Allium cepa, híbridos, produtividade, qualidade, precocidade.

\section{ABSTRACT}

\section{Agronomic performance and heterosis of onion genotypes}

The use of onion hybrids in Brazil is still recent, with little information regarding the gains from heterosis. However, the first step to exploit the heterosis is the evaluation of available germplasm. Due to the need for genotypes adapted to the climatic conditions of South-Central region of Paraná state, Brazil, this study aimed to evaluate the agronomic performance of 19 hybrids and 50 inbred lines of onion, as well as the heterotic gain of six of these hybrids. The experimental design was randomized blocks with three replications. The evaluated traits were yield, average weight of the bulbs, commercial classification of bulbs, waxy of the leaves and cycle. In general the hybrids were superior to the lineages in yield and average bulb weight and had lower cycle. The heterotic gain in hybrids was evident, indicating the viability of hybrids for cultivation in the region. Hybrids 2572, 2573 and 2578 are promising due their high yield, earliness cycle and better classification of the bulbs. The lineages 2507-1 and 2983 provided the highest heterotic gain for the yield of the hybrid 2857, which was classified in the group of earliest genotypes, showing an inverse correlation between these two characters.

Keywords: Allium cepa, hybrids, yield, quality, earliness.

\section{(Recebido para publicação em 23 de março de 2011; aceito em 5 de abril de 2012)} (Received on March 23, 2011; accepted on April 5, 2012)

\begin{abstract}
$\mathrm{A}$ cebola (Allium cepa) é a terceira hortaliça em importância econômica no mundo e no Brasil. Em 2008 a safra brasileira de cebola foi de 1.248 .173 toneladas, cultivada em 63.005 hectares, alcançando produtividade de $21,36 \mathrm{tha}^{-1}$ (Agrianual, 2009). O estado de Santa Catarina tem a maior produção nacional (31,7\%), enquanto o estado do Paraná é o quinto maior produtor, responsável por $8,4 \%$ da produção, e produtividade média de 17,16 t ha-1 (IBGE, 2008). Mais da metade da produção nacional concentra-se em propriedades familiares com menos de 20 hectares (Vilela et al., 2005), representando grande importância socioeconômica na cadeia produtiva
\end{abstract}

brasileira.

Um dos fatores que limitam a adoção de híbridos pelos produtores de cebola no estado do Paraná é a escassez de informações sobre o desempenho agronômico e a adaptação destes às condições edafoclimáticas das regiões produtoras (Resende et al., 2007). A cebola é uma hortaliça cuja adaptação é condicionada por fatores ambientais, notadamente o fotoperíodo e a temperatura. Se as condições climáticas não satisfizerem as exigências da cultura, pode haver perdas na produção, com redução da bulbificação, emissão precoce do pendão floral, formação de "charutos" e de bulbos pequenos (Resende et al., 2003). Além do mais, cuidados especiais devem ser tomados com a adubação, época de plantio, colheita, irrigação e escolha da cultivar (Kopsell \& Randle, 1997). Na busca de cultivares que atendam esses requisitos, e levando em consideração $\mathrm{o}$ efeito da interação genótipo $\mathrm{x}$ ambiente na cultura da cebola, o ideal é a identificação de híbridos adaptados e produtivos e a seleção das linhagens para produção de híbridos superiores na região de cultivo.

O ganho de produtividade por heterose tem sido o princípio usado em melhoramento e produção de muitas hortaliças de interesse agronômico (Maluf, 2001). A procura de híbridos pelos produtores 
de cebola tem aumentado em função da superioridade agronômica desses em relação às cultivares de polinização livre (May et al., 2007). Contudo, a utilização de híbridos no mercado nacional ainda é recente, sendo escassas as informações referentes às respostas agronômicas dos híbridos e das linhagens a serem utilizadas nos cruzamentos. Assim, informações referentes ao cultivo, como produção, massa média e qualidade dos bulbos, ciclo e resistência ou tolerância às principais doenças são informações importantes na determinação dos melhores híbridos e linhagens a fim de se obter o maior ganho heterótico em cruzamentos (Maluf, 2001).

Poucos são os trabalhos de pesquisa que avaliam o comportamento de novos híbridos e linhagens de cebola no estado do Paraná. Assim, devido à procura de genótipos promissores adaptados às condições climáticas paranaenses, o presente trabalho teve como objetivo avaliar o desempenho agronômico de híbridos e linhagens de cebola, bem como o ganho heterótico de alguns híbridos avaliados na região Centro-Sul do Paraná.

\section{MATERIAL E MÉTODOS}

O experimento foi realizado no município de Guarapuava, região Centro-Sul do Paraná (2523'36"S, $51^{\circ} 27^{\prime} 19^{\prime} \mathrm{W}$, altitude $\left.1.025 \mathrm{~m}\right)$. O clima da região é classificado como subtropical úmido mesotérmico $(\mathrm{Cfb})$ segundo classificação de Köppen, sem estação seca definida, com verões pouco quentes e invernos moderados (Thomaz \& Vestena, 2003). O solo da região é classificado como Latossolo Bruno Distroférrico típico, de textura argilosa (Embrapa, 2006).

O experimento foi realizado em 2008, quando foram avaliados híbridos e linhagens em desenvolvimento. Foram utilizados 19 híbridos (1266, 2572, 2573, 2575, 2578, 2579, 2580, 2898, 2899, 2902, 2903, 2904, 2906, 2909, 3111, 3112, 3113, 1324, 1555), 50 linhagens avançadas de cebola (2507-1, 2507-2, 2508-1, 2508-2, 2509-1, 25092, 2868-1, 2868-2, 2873-1, 2873-2, 2875-1, 2875-2, 3032-1, 3032-2, 30331, 3033-2, 3039-1, 3039-2, 3040-1,
3040-2, 3043-1, 3043-2, 3044-1, 30442, 3045-1, 3045-2, 3052-1, 3052-2, 3053-1, 3053-2, 3056-1, 3056-2, 2982, 2983, 2984, 2985, 2986, 2987, 2988, 2994, 2995, 2997, 3001, 3002, 3003, 3004, 3005, 3009, 3010, 3012) e a cultivar Bola Precoce Isla como testemunha. Os genótipos experimentais são propriedade da empresa Sakata Seeds Sudamerica Ltda. e são derivados de progênies desenvolvidas especificamente para a região sul do país, a partir de germoplasma nacional denominado Super Precoce e Crioula. Os híbridos possuem pelo menos uma das linhagens parentais avaliadas no experimento.

$\mathrm{O}$ delineamento experimental foi em blocos com os tratamentos casualizados com três repetições. As mudas foram produzidas em bandejas de isopor de 200 células, com substrato comercial. As bandejas foram mantidas sob casa de vegetação e irrigadas por microaspersão. As mudas foram transplantadas aos 55 dias após a semeadura, quando atingiram aproximadamente $20 \mathrm{~cm}$ de altura e 5 a 6 mm de diâmetro de pseudocaule, conforme recomendado por Vargas et al. (2007). Realizou-se o transplantio em canteiros de 1,20 m de largura e 0,25 m de altura, feitos com rotoencanteirador. As parcelas eram formadas por 20 linhas espaçadas em $15 \mathrm{~cm}$ com espaçamento de $10 \mathrm{~cm}$ entre plantas.

A adubação de base foi realizada com $600 \mathrm{~kg} \mathrm{ha}^{-1}$ de NPK (04-14-08), calculada com base em análise de solo. Aos 90 dias após o plantio realizaram-se duas adubações foliares com fertilizante líquido contendo $27 \%$ de $\mathrm{K}_{2} \mathrm{O}, 27 \%$ de $\mathrm{P}_{2} \mathrm{O}_{5}, 10 \%$ de cálcio e $2 \%$ de boro. Aos 115 dias aplicou-se em cobertura a dose equivalente a $150 \mathrm{~kg} \mathrm{ha}^{-1}$ de sulfato de amônio e cloreto de potássio na proporção 3:1. No manejo fitossanitário foram realizadas aplicações de defensivos agrícolas recomendados para a cultura. Para controlar as plantas daninhas foram feitas capinas manuais.

A cerosidade foliar foi avaliada aos 100 e 125 dias após o plantio, sendo o resultado composto pela média de duas avaliações. Utilizou-se escala de notas variando de 1 a 5 ( $1=$ sem cerosidade; $2=$ pouca cerosidade; $3=$ média cerosidade; 4= boa cerosidade; $5=$ folhas com muita cerosidade). Ferreira \& Costa (1983) classificavam a cebola em três grupos quanto a cerosidade: ceroso, intermediário e não ceroso. O grupo ceroso apresenta folhas com coloração verde-opaca devido à grande deposição de ceras na superfície foliar. $\mathrm{O}$ grupo intermediário compõe-se de plantas com folhas verde-opacas, porém de forma menos intensa, devido à menor presença de ceras na epiderme foliar. As plantas não cerosas caracterizam-se por um verde brilhante devido à ausência da cerosidade.

O ponto de colheita foi determinado pelo estalo (tombamento da parte aérea com folhas ainda verdes) de $80 \%$ das plantas em todas as parcelas. Comparou-se os genótipos pelo valor do total de dias transcorridos entre a data de semeadura e o estalo da planta. Após a colheita a parte aérea da planta foi eliminada e os bulbos foram armazenados em estrados de madeira em galpão. Após 15 dias de cura os bulbos foram contados, pesados e classificados de acordo com o seu diâmetro transversal (portaria 529 de 18 de março de 1995, MAPA), sendo: classe 1 (entre 15 e $35 \mathrm{~mm}$ ); classe 2 (entre 36 e $50 \mathrm{~mm}$ ); classe 3 (entre 51 e $60 \mathrm{~mm}$ ); classe 3 cheio (entre 61 e $70 \mathrm{~mm}$ ); e classe 4 (entre 71 e $90 \mathrm{~mm}$ ). Foi determinada a massa média de bulbos (g) e a produtividade $\left(\mathrm{t} \mathrm{ha}^{-1}\right)$ considerando $8.000 \mathrm{~m}^{2}$ de área útil.

As estimativas da heterose $(\mathrm{H})$ para as características avaliadas foram obtidas pela fórmula $\mathrm{H}=\mathrm{F}_{1}-\left(\mathrm{P}_{1}+\mathrm{P}_{2}\right) / 2$, em que: $\mathrm{F}_{1}=$ média da primeira geração oriunda do cruzamento (híbrido); $\mathrm{P}_{1}=$ média da linhagem parental $1 ; \mathrm{P}_{2}=$ média da linhagem parental 2. A heterose foi avaliada em seis híbridos que possuíam as duas linhagens parentais também avaliadas no experimento: 2573 $=\mathrm{F}_{1}(2507-1 \times 2982) ; 2575=\mathrm{F}_{1}$ (2509$1 \times 2982) ; 2578=\mathrm{F}_{1}(2507-1 \times 2983)$; $2579=\mathrm{F}_{1}(2508-1 \times 2983) ; 2580=\mathrm{F}_{1}$ $(2509-1 \times 2983)$ e $2899=\mathrm{F}_{1}(2873-1 \times$ 2982).

Os dados foram submetidos à análise de variância e as médias comparadas pelo teste de Skott-Knott $(\mathrm{p}<0,05)$. Visando estabelecer possíveis correlações (Pearson) entre os caracteres avaliados, foram determinados os coeficientes $\mathrm{r}$, testados pelo teste $\mathrm{t}(\mathrm{p}<0,05)$. Foi utilizado o programa estatístico Genes (Cruz, 2006). 


\section{RESULTADOS E DISCUSSÃO}

Os híbridos foram, em média 50\% mais produtivos que as linhagens, o que era de se esperar por se tratar de uma espécie alógama, que sofre depressão por endogamia (Hallauer \& Miranda Filho, 1995). Treze dos 20 híbridos apresentaram produtividade superior a $50 \mathrm{t}$ ha $^{-1}$. O híbrido 2572 foi o mais produtivo $\left(75,23 \mathrm{t} \mathrm{ha}^{-1}\right)$ e não diferiu significativamente dos híbridos 2578 e 2573 e da linhagem 2986 , a mais produtiva $(68,27$ $\mathrm{t} \mathrm{ha}^{-1}$ ) (Tabela 1). Apesar das produtividades alcançadas serem elevadas, em função do nível tecnológico adotado, esses valores estão de acordo com os observados por May et al. (2007), que obtiveram produtividades de $71 \mathrm{t} \mathrm{ha}^{-1} \mathrm{e}$ $64,8 \mathrm{t} \mathrm{ha}^{-1}$ com os híbridos Superex e Optima, respectivamente e Baier et al.
(2009) que obtiveram produtividades de até 92,20 t ha $^{-1}$ com o híbrido Buccaneer em elevada densidade populacional.

Entre as linhagens, cinco apresentaram produtividade superior a $45 \mathrm{tha}^{-1}$ (2986, 2509-2, 3002, 2508-1, 3044-2), demonstrando grande potencial para utilização em cruzamentos. Contudo, seis linhagens apresentaram produtividade inferior à média brasileira, 19,81 $\mathrm{tha}^{-1}$ (Agrianual, 2009).

A heterose média para produtividade foi de $52 \%$ (17,37 t ha $\left.{ }^{-1}\right)$, sendo que os híbridos mais produtivos 2578 e 2573 apresentaram heterose de 33,34 t ha $a^{-1}(79,86 \%)$ e 31,53 t ha $^{-1}(78,65 \%)$, respectivamente. A elevada heterose nos híbridos mais produtivos é muito interessante, pois valores de heterose elevados por si só não são sinônimos de alta produção, uma vez que a heterose é em relação à média dos genitores.

O potencial das linhagens em gerar híbridos heteróticos pode ser observado pelas diferentes combinações nos cruzamentos. A linhagem 2507-1 é genitora de dois dos híbridos mais produtivos, 2573 e 2578 , mostrando potencial para utilização em programas de melhoramento que visem à obtenção de híbridos. Por outro lado, a linhagem 2508-1 quando cruzada com a linhagem 2983 proporcionou heterose negativa $(-2,51$ t ha $^{-1}=-5,62 \%$ ) no híbrido 2579 , entretanto, essa mesma linhagem contribuiu para a elevada heterose dos híbridos 2578 e 2580 (Tabela 2). Esses resultados confirmam que o valor genético das linhagens para a obtenção de híbridos deve ser avaliado, principalmente, em função da capacidade específica de combinação dos cruzamentos em que

Tabela 1. Produtividade, massa média de bulbos, cerosidade foliar e ciclo dos genótipos de cebola que se destacaram, favoravelmente ou desfavoravelmente, no experimento (yield, average bulb weight, leaf wax, and cycle of better and worst onion genotypes during experiment onset). Guarapuava, UNICENTRO, 2009.

\begin{tabular}{|c|c|c|c|c|}
\hline Genótipo & $\begin{array}{c}\text { Produtividade } \\
\text { (t/ha) }\end{array}$ & $\begin{array}{c}\text { Massa média de bulbos } \\
(\mathrm{g})\end{array}$ & $\begin{array}{c}\text { Cerosidade foliar } \\
(\%)\end{array}$ & $\begin{array}{l}\text { Ciclo } \\
\text { (dias) }\end{array}$ \\
\hline Híbrido 1266 & $47,54 \mathrm{~d}$ & $139,94 \mathrm{~b}$ & $3,33 \mathrm{~b}$ & $205,67 \mathrm{~b}$ \\
\hline Híbrido 2572 & 75,23 a & $178,57 \mathrm{a}$ & $3,33 \mathrm{~b}$ & $196,00 \mathrm{c}$ \\
\hline Híbrido 2573 & $71,62 \mathrm{a}$ & $175,00 \mathrm{a}$ & $3,67 \mathrm{~b}$ & $192,00 \mathrm{~d}$ \\
\hline Híbrido 2575 & $49,48 \mathrm{~d}$ & $152,92 \mathrm{~b}$ & $3,00 \mathrm{c}$ & $204,33 \mathrm{~b}$ \\
\hline Híbrido 2578 & 75,08 a & $180,11 \mathrm{a}$ & $3,83 \mathrm{~b}$ & $188,00 \mathrm{~d}$ \\
\hline Híbrido 2580 & $64,17 \mathrm{~b}$ & $151,04 \mathrm{~b}$ & $3,00 \mathrm{c}$ & $190,33 \mathrm{~d}$ \\
\hline Híbrido 2903 & $54,06 \mathrm{c}$ & $140,79 \mathrm{~b}$ & $3,17 \mathrm{c}$ & $194,33 \mathrm{c}$ \\
\hline Híbrido 2904 & $50,33 \mathrm{~d}$ & $122,16 \mathrm{c}$ & $3,00 \mathrm{c}$ & $193,67 d$ \\
\hline Híbrido 1324 & $38,63 \mathrm{e}$ & $92,06 \mathrm{e}$ & $3,50 \mathrm{~b}$ & $214,00 \mathrm{a}$ \\
\hline Bola Precoce & $41,82 \mathrm{e}$ & $101,75 \mathrm{~d}$ & $4,33 \mathrm{a}$ & $211,33 \mathrm{a}$ \\
\hline Linhagem 2507-1 & $42,30 \mathrm{e}$ & $104,05 \mathrm{~d}$ & $3,00 \mathrm{c}$ & $197,00 \mathrm{c}$ \\
\hline Linhagem 2507-2 & $36,57 \mathrm{f}$ & 89,76 e & $2,67 \mathrm{c}$ & $198,67 \mathrm{c}$ \\
\hline Linhagem 2508-1 & $48,23 \mathrm{~d}$ & $112,57 \mathrm{~d}$ & $3,50 \mathrm{~b}$ & $201,67 \mathrm{~b}$ \\
\hline Linhagem 2509-2 & $48,87 \mathrm{~d}$ & $118,11 \mathrm{~d}$ & $3,50 \mathrm{~b}$ & $206,67 \mathrm{~b}$ \\
\hline Linhagem 3039-1 & $39,02 \mathrm{e}$ & $90,71 \mathrm{e}$ & $3,50 \mathrm{~b}$ & $214,00 \mathrm{a}$ \\
\hline Linhagem 3039-2 & $41,79 \mathrm{e}$ & $108,22 \mathrm{~d}$ & $3,67 \mathrm{~b}$ & $211,33 \mathrm{a}$ \\
\hline Linhagem 3044-2 & $46,25 \mathrm{~d}$ & $109,79 \mathrm{~d}$ & $3,17 \mathrm{c}$ & $198,67 \mathrm{c}$ \\
\hline Linhagem 3056-1 & $23,42 \mathrm{~g}$ & $78,91 \mathrm{f}$ & $3,83 \mathrm{~b}$ & $205,00 \mathrm{~b}$ \\
\hline Linhagem 2983 & $41,19 \mathrm{e}$ & $117,71 \mathrm{~d}$ & $3,00 \mathrm{c}$ & $200,67 \mathrm{~b}$ \\
\hline Linhagem 2986 & $68,27 \mathrm{a}$ & 187,29 a & $2,50 \mathrm{c}$ & $205,00 \mathrm{~b}$ \\
\hline Linhagem 3002 & $48,76 \mathrm{~d}$ & $136,53 \mathrm{c}$ & $3,67 \mathrm{~b}$ & $202,00 \mathrm{~b}$ \\
\hline Linhagem 3004 & $7,85 \mathrm{i}$ & $48,68 \mathrm{~g}$ & $2,67 \mathrm{c}$ & $214,00 \mathrm{a}$ \\
\hline CV $(\%)$ & 8,70 & 9,07 & 43,07 & 2,36 \\
\hline
\end{tabular}

Médias seguidas pela mesma letra na coluna não diferem estatisticamente pelo teste de Skott-Knott $(\mathrm{p}<0,05)($ averages followed by same letter in column do not differ statistically according to Skott-Knott test $(\mathrm{p}<0,05))$. 
Tabela 2. Valores de heterose de seis híbridos de cebola em relação à média dos genitores para as características produtividade, massa média de bulbos e ciclo (heterosis values of six onion hybrids in relation to parents average for characteristics of yield, bulb average weight and cycle). Guarapuava, UNICENTRO, 2009.

\begin{tabular}{|c|c|c|c|c|c|c|}
\hline \multirow{2}{*}{ Híbrido } & \multicolumn{2}{|c|}{ Produtividade } & \multicolumn{2}{|c|}{ Massa média } & \multicolumn{2}{|c|}{ Ciclo } \\
\hline & $\left(t h^{-1}\right)$ & $(\%)$ & (g) & $(\%)$ & (dias) & $(\%)$ \\
\hline 2573 & 31,53 & 78,65 & 75,37 & 75,66 & $-8,67$ & $-4,32$ \\
\hline 2575 & 8,09 & 19,53 & 49,90 & 48,44 & 0,17 & 0,08 \\
\hline 2578 & 33,34 & 79,86 & 69,23 & 62,44 & $-10,83$ & $-5,45$ \\
\hline 2579 & $-2,51$ & $-5,62$ & 1,89 & 1,64 & $-5,17$ & $-2,57$ \\
\hline 2580 & 21,12 & 49,06 & 36,77 & 32,18 & $-12,00$ & $-5,93$ \\
\hline 2899 & 12,67 & 33,26 & 14,84 & 15,23 & $-7,67$ & $-3,79$ \\
\hline
\end{tabular}

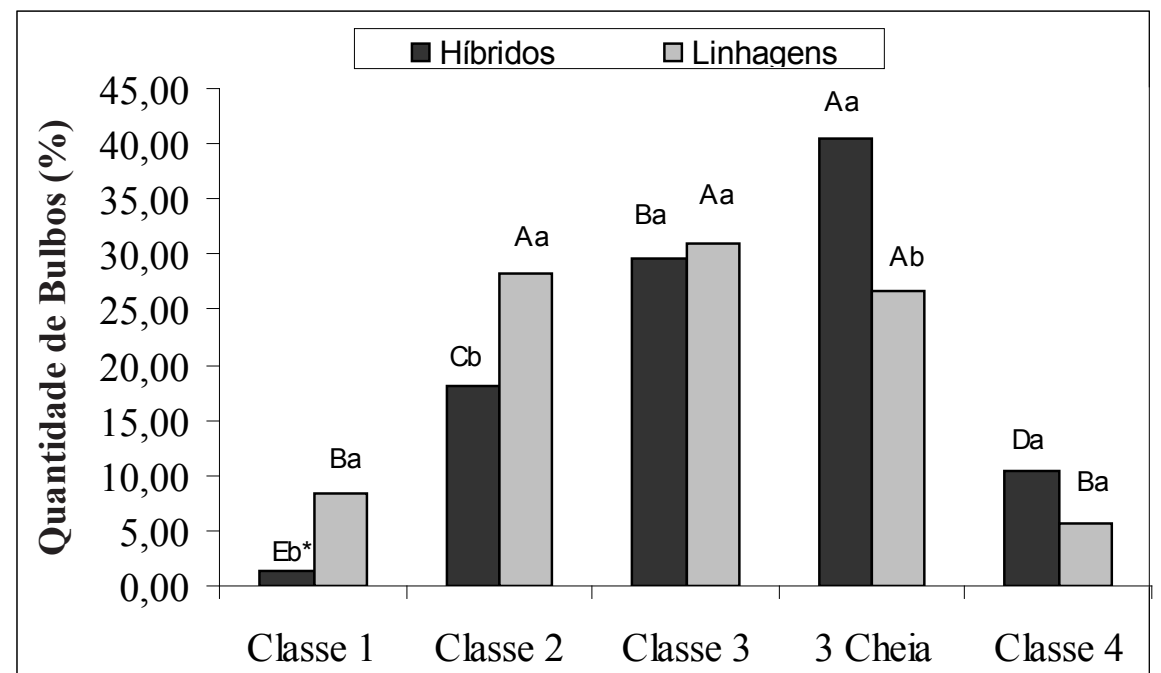

Figura 1. Classificação comercial, média dos 19 híbridos e 50 linhagens de cebola cultivados na região Centro-Sul do Paraná (average commercial classification of 19 hybrids and 50 lineages of onion cultivated in Paraná Center South region. Guarapuava, UNICENTRO, 2009. *Colunas seguidas pelas mesmas letras minúsculas em cada classe e maiúsculas entre as diferentes classes, não diferem estatisticamente ente si pelo teste de Skott-Knott $(p<0,05)$ (*columns followed by same lowercase letters in each class and capital letters between different classes do not differ statistically among themselves according to Skott-Knott $(\mathrm{p}<0,05)$ test $)$.

Tabela 3. Correlações entre produtividade, massa média de bulbos, cerosidade foliar e ciclo entre 19 híbridos e 50 linhagens de cebola cultivadas na região Centro-Sul do Paraná (correlation between yield, average bulb weight, leaf wax, and cycle among 19 hybrids and 50 lineages of onion cultivated in Paraná Center South region). Guarapuava, UNICENTRO, 2009.

\begin{tabular}{lccc}
\hline & $\begin{array}{c}\text { Produtividade } \\
\left(\mathbf{t} \mathbf{~ h a}^{-1}\right)\end{array}$ & $\begin{array}{c}\text { Massa média } \\
\mathbf{d e ~ b u l b o s}(\mathbf{g})\end{array}$ & $\begin{array}{c}\text { Cerosidade } \\
(\mathbf{\%})\end{array}$ \\
\hline Massa média de bulbos & $0,92^{* *}$ & & \\
Cerosidade & $0,45^{\text {ns }}$ & $0,35^{\text {ns }}$ & $-0,20^{\text {ns }}$ \\
Ciclo (dias) & $-0,60^{*}$ & $-0,53^{*}$ & of \\
$\begin{array}{l}\text { *,**significativos a } 5 \text { e } 1 \% \text { de probabilidade pelo teste } \mathrm{t}\left({ }^{*}, * * \text { significant at } 5 \text { and } 1 \% \text { of }\right. \\
\text { probability by t test). }\end{array}$
\end{tabular}

estas participam. A direção e a magnitude da heterose para um determinado caráter dependem da divergência entre os genótipos (Santos et al., 2011) e da
(Hallauer \& Miranda Filho, 1995).

Os valores de heterose para a produtividade observados nesse estudo são muito superiores aos observados em outras hortaliças: pepino, 16,4\% (Godoy et al., 2008), pimentão, 7,68\% (Gomide et al., 2003) e tomate, $-19,47$ a $2,41 \%$ (Freitas et al., 1999). É de se esperar que, de modo geral, as olerícolas autógamas apresentem heterose menos expressiva em comparação com as alógamas (Maluf, 2001). Evoor et al. (2007) obtiveram variação na heterose para produção de bulbos de cebola comercializáveis de $-30,14 \%$ a $45,31 \%$. Esses mesmos autores também encontraram valores com elevada amplitude para a heterobeltiose (-43,12\% a 31,01\%), contudo, a heterobeltiose não foi calculada nesse estudo devido às pequenas diferenças entre as linhagens genitoras utilizadas. Por outro lado, Abubakar \& Ado (2008) avaliaram a heterose para produtividade de bulbos frescos de cebola e observaram heterose negativa em 19 dos 20 híbridos avaliados, com valores que variavam entre $-72,97$ a $17,26 \%$.

A massa média de bulbos para híbridos e linhagens variou de 92,0 a 178,5 g e 40,3 a $187,29 \mathrm{~g}$, respectivamente (Tabela 1). Esses valores são muito superiores aos relatados por Resende $e t$ al. (2003), que observaram variações na massa média de 45,99 a 97,69 g para as cultivares Chata Roxa e Granex, respectivamente, cultivadas no Sul de Minas Gerais. Por outro lado, estão de acordo com os observados por Resende et al. (2007) na região Centro-Sul do Paraná, que observaram valores variando entre 52,13 e $159 \mathrm{~g}$, com destaque para o híbrido Buccanner.

A heterose para massa média de bulbos foi similar à observada para a produtividade, sendo a heterose média dos seis híbridos de 41,33 g (39,27\%). Os maiores valores foram também observados nos híbridos $2573(75,37 \mathrm{~g}$ $=75,66 \%)$ e $2578(69,23 \mathrm{~g}=62,44 \%)$ (Tabela 2). Esses resultados confirmam a correlação positiva e a elevada magnitude entre esses dois caracteres (Tabela 3 ). Esses valores de heterose são muito superiores aos obtidos por Evoor et al. (2007) que avaliaram 30 híbridos de cebola e observaram heterose variando de $-39,69$ até $6,25 \%$ e aos observados por 


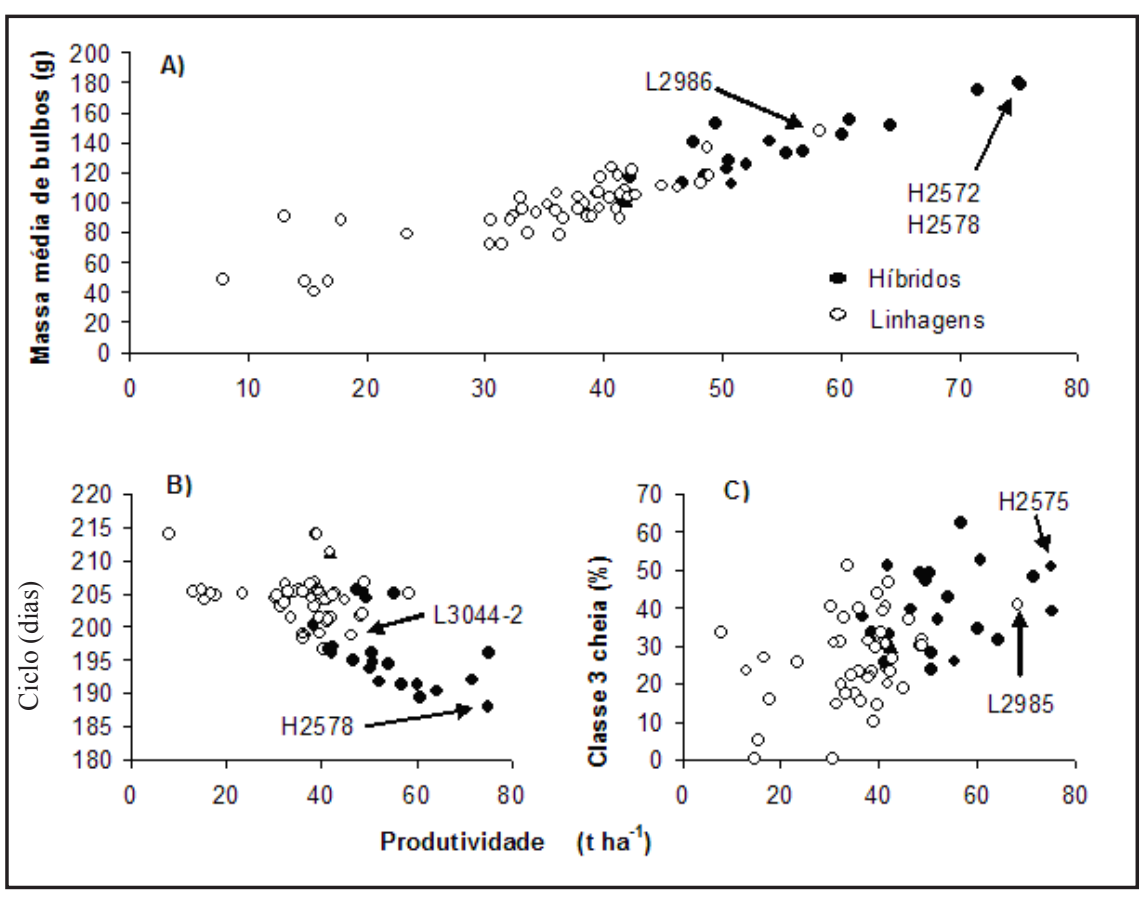

Figura 2. Relação da produtividade dos 19 híbridos e 50 linhagens de cebola com a massa média de bulbos, ciclo e classificação comercial 3 cheia, avaliada na região Centro-Sul do Paraná (relation of 19 hybrids and 50 onion lineages productivity with average bulb mass, cycle and commercial classification 3 full, evaluated in Paraná Center South region). Guarapuava, UNICENTRO, 2009.

Abubakar \& Ado (2008), que avaliaram 20 híbridos e verificaram valores de heterose entre $-22,99$ e $62,48 \%$.

Os genótipos foram divididos em três grupos quanto à cerosidade foliar, contudo, as diferenças entre e dentre os grupos foi pequena (Tabela 1). Esse caráter apresentou também elevado coeficiente de variação e, sendo assim, a metodologia adotada neste trabalho não foi suficiente para distinção de genótipos. Cabe ressaltar que a cerosidade foliar é uma característica desejável, pois pode ser diretamente correlacionada com a maior tolerância a estresses ambientais e a menor incidência de patógenos que causam lesões foliares (Ferreira \& Costa, 1983). Esses mesmos autores também constataram que, tanto o grau de cerosidade natural quanto a capacidade de regenerar a camada cerosa após dano, são características genéticas, com grande variação entre cultivares de cebola e que podem ser exploradas em programas de melhoramento da cultura.

Quanto ao ciclo de cultivo, a testemunha Bola Precoce, o híbrido 1324 e três linhagens (3039-1, 3039-2 e 3004) foram classificados no grupo de genótipos mais tardios (Tabela 1). O híbrido mais precoce foi o 2578 (188 dias), contudo não diferiu de outros sete híbridos. As linhagens tiveram ciclo médio de 203 dias e, apesar de existirem diferenças entre as mesmas, essas são de poucos dias. De maneira geral, houve prolongamento do ciclo nos genótipos avaliados, provavelmente devido às temperaturas mais baixas no período de cultivo, típico da região de Guarapuava, em relação às demais regiões produtoras de cebola. Contudo, a maior parte dos genótipos avaliados foi mais precoce do que a testemunha, devido estes serem provenientes de progênies derivadas de germoplasma denominado 'super precoce'.

A heterose para ciclo foi negativa na maioria dos híbridos avaliados e variou de $-5,93$ a $0,08 \%$ (Tabela 2), obtendo-se ganho heterótico em precocidade de até 12 dias para o híbrido 2580. Abubakar \& Ado (2008) avaliaram a heterose para maturidade de 20 híbridos de cebola e obtiveram estimativas que variaram de $-2,85 \%$ a $41,99 \%$, observando-se em dez casos heterose positiva e em dez casos heterose negativa. A redução do ciclo é uma importante característica que pode ser levada em consideração em pro- gramas de melhoramento, pois quanto mais precoce a cultura, melhor será o aproveitamento da terra, aumentando, consequentemente, a rentabilidade da cultura.

Com relação à classificação comercial dos bulbos, a superioridade dos híbridos em relação às linhagens foi evidente (Figura 1). Os híbridos, de maneira geral, apresentaram poucos bulbos na classificação comercial 1 e 4, concentrando-se na classe 3 cheia, preferida comercialmente. Por outro lado, as linhagens produziram quantidades equivalentes de bulbos nas classes 2 , 3 e 3 cheia, não havendo diferenças entre essas classes. Na classe 3 cheia três híbridos (2572, 2573 e 2906) apresentaram valores superiores aos demais (dados não apresentados), podendo esse ser um bom critério para seleção de genótipos superiores. A maior concentração dos bulbos dos híbridos na classe 3 cheia, classe relacionada com a qualidade da produção (Reghin et al., 2006; Resende et al., 2007), é um bom indício de que, além de serem mais produtivos, os híbridos produziram bulbos de melhor qualidade comercial. A importância desta classe, segundo Silva et al. (1991), se deve ao mercado consumidor nacional preferir bulbos de tamanho médio, com massa média de 80 a 100 gramas e diâmetro transversal entre 40 a $80 \mathrm{~mm}$.

Outra maneira que permite visualizar os melhores híbridos e linhagens é por meio da comparação dos caracteres conjuntamente, dois a dois (Figura 2). Sendo assim, três caracteres foram analisados junto com a produtividade, que é o principal fator a ser levado em consideração. Houve correlação positiva e significativa entre produtividade e massa média de bulbos (Tabela 3), destacando-se nesse caso os híbridos 2572 e 2578 como os mais promissores (Figura 2A). Quanto ao ciclo, destacou-se o híbrido 2578 e a linhagem 30442 , sendo que esta última foi agrupada próxima às outras linhagens (Figura 2B). Por último, na classe comercial 3 cheia destacaram-se o híbrido 2575 e a linhagem 2985 (Figura 2C). O ciclo foi correlacionado negativamente com a produtividade $(\mathrm{r}=-0,60)$ (Tabela 3$)$; sendo assim, houve redução do ciclo 
com o aumento da produtividade da cultura. Resultados semelhantes foram observados por Abubakar \& Ado (2008) que observaram correlação do ciclo da cultura de 0,67 e 0,95 com a massa e o diâmetro do bulbo, respectivamente.

De forma sucinta, conclui-se que: i) os híbridos 2572, 2573 e 2578 são promissores, pois aliam alta produtividade, ciclo mais precoce e boa classificação de bulbos comerciáveis; ii) as linhagens 2986, 2509-2, 3002 e 3044-2 possuem elevada produtividade, sendo promissoras para a obtenção de híbridos; iii) as linhagens 2507-1 e 2983 proporcionam elevado ganho heterótico para a produtividade do híbrido 2857, o qual foi classificado no grupo de genótipos mais precoces, demonstrando a existência de correlação inversa entre esses dois caracteres; iv) apesar de existirem diferenças quanto à cerosidade foliar, nenhum genótipo se destacou e não houve heterose para essa característica; v) o híbrido 2580 apresentou maior ganho heterótico para redução do ciclo, havendo, na maioria dos casos, heterose negativa para essa característica; vi) os híbridos produzem bulbos com maior qualidade comercial (classe 3 cheia) que as linhagens.

\section{REFERÊNCIAS}

AGRIANUAL. 2009. Anuário da agricultura brasileira. São Paulo: Instituto Agronômico FLP, Consultoria e comércio. 497 p.

ABUBAKAR L; ADO SG. 2008. Heterosis of purple blotch (Alternaria porri (Ellis) Cif) resistance, yield and earliness in tropical onions (Allium cepa L.). Euphytica 164: 63-74.

BAIER JE; RESENDE JTV; GALVÃO AG; BATTISTELLI GM; MACHADO, MM; FARIA MV. 2009. Produtividade e rendimento comercial de bulbos de cebola em função da densidade de cultivo. Ciência e Agrotecnologia 33: 496-501.

CRUZ CD. 2006. Programa Genes - Estatística Experimental e Matrizes. Viçosa: Editora UFV, v1, $285 \mathrm{p}$.

EMPRESA BRASILEIRA DE PESQUISA AGROPECUÁRIA. 2006. Sistema brasileiro de classificação de solos. Rio de Janeiro: Embrapa Solos. 306 p.

EVOOR S; GOWDA R; GANGAPPA E; MONOHAR RK. 2007. Heterosis for yield, yield components and quality traits in onion (Allium cepa L.). Karnataka Journal of Agricultural Sciences 20: 813-815.

FERREIRAPV; COSTACP. 1983. Comportamento varietal de cebola (Allium cepa $\mathrm{L}$ ) do grupo ceroso em relação á velocidade de reposição de cera foliar. Brazilian Journal of Genetics 6: 709-717.

FREITAS JA; MALUF WR; AZEVEDO SM; BRAGA RS; GOMES LAA. 1999. Efeito dos alelos alc, $\mathrm{og}^{\mathrm{c}}$, hp e heterose em características de produção do tomateiro. Acta Scientiarum 21: 439-446.

GODOY AR; HIGUTI ARO; CARDOSO AII 2008. Produção e heterose em cruzamentos entre linhagens de pepino do grupo caipira. Bragantia 67: 839-844.

GOMIDE ML; MALUF WR; GOMES LAA. 2003. Heterose e capacidade combinatória de linhagens de pimentão (Capsicum annuum L.). Ciência e Agrotecnologia 27:1007-1015.

HALLAUER AR; MIRANDA FILHO JB. 1995. Quantitative genetics in maize breeding. $2^{\text {nd }}$ ed. Ames: Iowa State University Press, 468p.

IBGE. 2008. Levantamento Sistemático da Produção Agrícola. Rio de Janeiro, 20: 1-76.

KOPSELL DA; RANDLE WM. 1997. Short-day onion cultivars differ in bulb selenium and sulfur accumulation which can affect bulb pungency. Euphytica 96: 385-390.

MALUF WR. 2001. Heterose e emprego de híbridos F1 em hortaliças. In: NASS LL; VALOIS ACC; MELO IS; VALADARES MC (eds). Recursos genéticos e melhoramento de plantas. Rondonópolis: Fundação MT. p.327-356.

MAY A; CECÍLIO FILHO AB; PORTO DRQ; VARGAS PF; BARBOSA JC. 2007. Produtividade de híbridos de cebola em função da população de plantas e da fertilização nitrogenada e potássica. Horticultura Brasileira 25: 53-59.

REGHIN MY; OTTO RF; OLINIK JR; JACOBY CFS. 2006. Produção de cebola sobre palhada a partir de mudas obtidas em bandejas com diferentes números de células. Horticultura Brasileira 24: 414-420.

RESENDE GM; CHAGAS SJR; PEREIRA L. 2003. Características produtivas de cultivares de cebola no Sul de Minas Gerais. Horticultura Brasileira 21: 722-725.

RESENDE JT; PIRES DB; CAMARGO LK; MARCHESE A. 2007. Desempenho produtivo de cultivares de cebola em Guarapuava, Paraná. Ambiência 3: 193-199.

SANTOS CAF; OLIVEIRA VR; RODRIGUES MA; RIBEIRO HLC; SILVA GO. 2011. Similaridade genética entre cultivares de cebola de diferentes tipos e origens, baseada em marcadores AFLP. Horticultura Brasileira 29: 32-37.

SILVA E; TEIXEIRA LAJ; AMADO TJC. 1991. The increase in onion production in Santa Catarina State, South Brazil. Onion Newsletter for the Tropics 3: 7-9.

THOMAZ EL; VESTENA LR. 2003. Aspectos climáticos de Guarapuava-PR. Guarapuava: UNICENTRO. $106 \mathrm{p}$.

VARGAS PF; BRAZ LT; MAY A. 2007. Produtividade de cultivares de cebola em função do número de mudas por célula de bandeja e espaçamento entre covas. Horticultura Brasileira 25: 241-245.

VILELA NJ; MAKISHIMA N; OLIVEIRA R; COSTA ND; MADAIL JCM; CAMARGO FILHO W; BOEING G; MELO PCT. 2005. Desafios e oportunidades para o agronegócio de cebola no Brasil. Horticultura Brasileira 23: 1029-1033. 